\title{
APOSENTA-AÇÃO: programa de preparação para aposentadoria
}

\author{
Dulce Helena Penna Soares ${ }^{1}$ \\ Aline Bogoni Costa ${ }^{2}$ \\ Alexandre Matos Rosa ${ }^{3}$ \\ Maria Lúcia S. de Oliveira ${ }^{4}$
}

\section{Resumo}

Este artigo apresenta reflexões acerca do tema aposentadoria e descreve as etapas de desenvolvimento do Programa de Preparação para Aposentadoria Aposenta-Ação. Evidenciou-se, por meio da bibliografia consultada e do referido Programa, que a aposentadoria, para a grande maioria das pessoas, não é acompanhada de reflexões sobre o projeto de futuro e, em decorrência disso, oportuniza-se o aparecimento de diversos problemas de ordem psicológica e social. Conclui-se que o trabalho de orientação e acompanhamento psicológico na fase de aposentadoria constituiu-se em facilitador fundamental para enfrentar esta nova etapa da vida.

Palavras-chave: Aposentadoria. Programa de Preparação. Orientação.

\section{Psicologia e Preparação para a Aposentadoria}

O tema aposentadoria tem despertado discussões em diversos campos profissionais. Especificamente na Psicologia, destacam-se estudos sobre as percepções sociais formuladas sobre esse conceito, questões relativas ao envelhecimento, reflexões sobre o lugar do trabalho para o homem e para a sociedade e as decorrências psicológicas resultantes da dificuldade de adaptação frente ao rompimento com o trabalho.

Este artigo corrobora com a produção científica sobre o tema, re-

\footnotetext{
${ }^{1}$ Coordenadora do Laboratório de Informação e Orientação Profissional (LIOP). Professora do Departamento de Psicologia e do Programa de Pós-Graduação em Psicologia da Universidade Federal de Santa Catarina. Doutora em Psicologia Clínica na França. Bolsista Produtividade CNPQ. E-mail: dulce@cfh.ufsc.br

${ }^{2}$ Graduada em Administração de Empresas pela Universidade do Estado de Santa Catarina. Formanda do Curso de Psicologia da Universidade Federal de Santa Catarina. Mestranda do Curso de Psicologia da Universidade Federal de Santa Catarina. E-mail: aline_bogoni@yahoo.com.br

${ }^{3}$ Psicólogo pela Universidade Federal de Santa Catarina. Pós-graduando pelo Instituto Catarinense de Pósgraduação . E-mail: alexandrematosrosa@gmail.com

${ }^{4}$ Psicóloga pela Universidade Federal de Santa Catarina. E-mail: marluseol@gmail.com
}

Estud. interdiscip. envelhec., Porto Alegre, v. 12, p. 143-161, 2007. 
latando as experiências obtidas com o desenvolvimento do Programa de Preparação para a Aposentadoria Aposenta-Ação, cujos objetivos e abordagens utilizadas estão descritos neste trabalho.

A produção científica sobre preparação para aposentadoria em Psicologia é quantitativamente pequena. Tal afirmação fundamenta-se em pesquisa realizada em base de dados eletrônica ${ }^{5}$, com a combinação das palavras-chaves: aposentadoria, preparação e psicologia.

Primeiramente, com palavras aposentadoria e preparação, a pesquisa obteve um total de dez resultados, sendo quatro referentes à temática do envelhecimento humano e seis direcionados à preparação para aposentadoria, dos quais se destacam, devido à vinculação também com a Psicologia, os estudos de França (1999) e Rodrigues et al. (2005).

Combinando-se as palavras aposentadoria e psicologia, obteve-se um total de quarenta e quatro estudos (dos quais quatro repetidos da primeira pesquisa), cujas temáticas, na grande maioria, são voltadas para as questões relativas à saúde do idoso e envelhecimento. Destacam-se deste grupo os estudos de Witczak (2001), Amarilho (2005) e Both (2004).

A compreensão da aposentadoria implica reflexões sobre os sentidos e significados do trabalho para o homem e para a sociedade. As definições do termo aposentadoria, socialmente disseminadas, deixam isto evidente. Conforme Ferreira (1986, p. 118), aposentadoria é um: "Estado de inatividade de funcionário público ou de empresa particular, ao fim de certo tempo de serviço, com determinado vencimento." Ao analisar esta definição cabe o questionamento: para o homem ser ativo, é preciso que esteja trabalhando?

Outra definição do mesmo autor (FERREIRA, 1986) remete a recolhimento e alojamento. Segundo Carlos et al. (1999), atribui-se ao vocábulo aposentadoria, na língua portuguesa, a idéia de recolhimento ao interior da habitação. Para serem mais específicos e compreenderem etimologicamente a denominação "aposentadoria", os autores substituem a palavra "habitação" por "aposentos", apresentando, desta forma, o conceito de aposentadoria como o recolhimento ao interior dos aposentos. Tal definição leva a novo questionamento: estar aposentado para o homem

\footnotetext{
${ }^{5}$ A pesquisa foi realizada na data de 13 de junho de 2007 nas bases de dados que integram: Index Psi Periódicos Técnico-Científicos, Index Psi Periódicos de Divulgação Científica, Index Psi Teses, LILACS — Literatura Latinoamericana e do Caribe em Ciências da Saúde, PEPsic — Periódicos Eletrônicos em Psicologia e Scielo.
} 
significa estar isolado, não ter relacionamentos sociais e estar 'internado' aos aposentados, como se estivesse doente?

A partir destes questionamentos, fica evidenciado que, tanto na conceituação do termo aposentadoria, como nas percepções sociais formuladas a respeito desta etapa de vida, o aposentar-se está vinculado à perda da capacidade de ação do sujeito, um movimento de tornar-se inativo, improdutivo, ou seja, alguém passivo aos acontecimentos sociais. Para Rodrigues et al. (2005), essa passividade confere ao sujeito uma espécie de morte social, tendo em vista que a aposentadoria é, por vezes, vivenciada como a perda do próprio sentido da vida.

$\mathrm{O}$ ato de aposentar-se impõe conflitos permeados pelo papel central do trabalho no processo de constituição identitária dos sujeitos, especialmente na sociedade atual que preceitua a supervalorização da produtividade e do capital. De forma simplista, o homem aposentado está na contramão do projeto social de sujeito trabalhador ao qual se condicionou durante a maior parte da vida.

Acerca da centralidade do trabalho para o homem, Marx (1984) define o trabalho como responsável pelo processo denominado de hominização, constituindo-se como condição básica para a emancipação humana. Por meio do trabalho o homem modifica e transforma o mundo, ao mesmo tempo em que se transforma e se humaniza.

Diante disso, é compreensível a importância e a valorização dadas ao trabalho pelo homem, pois este se constitui em uma das principais fontes de significados para os sujeitos. Segundo Zanelli e Silva (1996), por meio do trabalho o indivíduo reconfigura a percepção de si mesmo e do seu ambiente, possibilitando, com isto, seu crescimento e desenvolvimento pessoal. O trabalho é, pois, uma categoria central não somente para a organização da vida social, mas também na dimensão psicológica, pois é fundamental para os processos de auto-descrição e auto-avaliação do sujeito.

Há, por outro lado, ambigüidades presentes ao trabalhar e se aposentar. Segundo Dejours et al. (1994), o trabalho, ao mesmo tempo em que é fonte de satisfação e realização, também é fonte de sobrevivência e sofrimento. Para Santos (1990), o afastamento do trabalho também gera sentimentos ambíguos, uma vez que o sujeito se depara tanto com o sentimento de crise quanto com o de liberdade. $\mathrm{O}$ autor apresenta duas formas, geralmente concomitantes, de lidar com a aposentadoria: crise — pela re- 
cusa em aceitar a condição de aposentado, especialmente devido à imagem estigmatizada vinculada à inatividade que tal condição confere; liberdade - sentimento resultante da busca pelo prazer em atividades de lazer e concretização de planos anteriormente não possíveis de se realizarem pelo compromisso/obrigação de trabalhar. Witczak (2005) compartilha de opinião semelhante ao afirmar que os sentimentos são antagônicos com relação à saída definitiva do mundo do trabalho. Por um lado, as pessoas sentem-se libertas do relógio, e, por outro, pesa-lhes a falta da rotina de tantos anos.

Costuma-se conferir à aposentadoria a idéia de liberdade, como sendo naturalmente previsível, neste momento de vida, poder descansar, poder fazer somente o que se quer, etc. Segundo Bernhoeft (1994), o descanso ou o desfrute está, culturalmente, vinculado a uma concepção de prêmio subseqüente a uma árdua dedicação ao trabalho. Zanelli e Silva (1996) corroboram com esta idéia, afirmando que a aposentadoria é vista como um prêmio, um júbilo, uma recompensa aos esforços depreendidos ao longo de uma carreira de trabalho, possibilitando ao sujeito a concretização de planos ou sonhos que foram protelados por muito tempo.

Para Witczak (2005), o sentimento de desamparo, de ruptura com o estabelecido é pesado e penoso, tendo em vista que, para muitos, o ambiente de trabalho é um verdadeiro lar. Após aposentados legalmente, muitos continuam exercendo suas atividades, inclusive nas mesmas empresas.

O evento da aposentadoria não afeta somente o indivíduo, mas também aqueles que o cercam, pois a dedicação quase exclusiva à identidade de trabalhador acaba, em muitos casos, por prejudicar o desempenho dos demais papéis sociais, dentre os quais o familiar. A vida conjugal e o convívio com os filhos costumam ser deixados de lado, e o retorno ao lar, após a aposentadoria, faz com que o sujeito estranhe ou até mesmo desconheça verdadeiramente as pessoas com as quais convive. Estes fatores também influenciam negativamente neste processo de transição de um papel ativo e produtivo para a nova situação que se configura.

Destaca-se, portanto, a importância de se construírem novas fontes de satisfação com a aposentadoria, substituindo-se os estímulos gratificantes relacionados à identidade profissional por novas formas de busca pelo prazer. Essa nova etapa pode ser tão gratificante quanto as vivências das fases anteriores, desde que possibilite o desenvolvimento pessoal, preservando-se a auto-estima e desvinculando-se a idéia na qual só se obtém 
satisfação por meio de atividades laborativas.

A aposentadoria nem sempre implica o afastamento do mundo do trabalho, quer seja pela necessidade de complementação financeira, ou mesmo pela necessidade de sentir-se ativo, em uma sociedade na qual o homem vale pelo que possui, pelo cargo ocupado, pelo status adquirido em sua relação com a atividade profissional desempenhada. A dificuldade em se afastar da atividade laborativa tende a ser proporcional ao grau de satisfação obtido, seja no desempenho do trabalho em si ou no grupo formado por intermédio do trabalho (ZANELLI; SILVA, 1996).

A partir dessas considerações, a preparação para a aposentadoria torna-se essencial, na medida em que a ambigüidade de sentimentos, característicos desta nova etapa da vida, pode ter conseqüências em outras áreas da vida, sendo a família o principal alvo destas inadequações. Para o indivíduo, as decorrências negativas podem favorecer o adoecimento, tanto físico quanto emocional, especialmente em função das somatizações, impactando, sobretudo, na auto-estima da pessoa.

Como proposta de trabalho em Psicologia, a seguir apresenta-se a experiência do Programa de Preparação para Aposentadoria AposentaAção realizado por meio de atividades grupais e colaboração de profissionais de diversas áreas.

\section{A Experiência de Criação do Programa Aposenta-Ação}

Como discutido anteriormente, ao se falar em aposentadoria, uma série de ambigüidades e questionamentos surgem: O que esse novo período trará a minha vida? O que poderá mudar? Será melhor? Como ficará o meu relacionamento social? Com intuito de auxiliar as pessoas que estão prestes a se aposentar ou recém-aposentadas, na busca de respostas a suas questões e autoconhecimento, foi elaborado o Programa de Preparação para a Aposentadoria Aposenta-Ação.

As atividades foram iniciadas no ano de 2006 com a pretensão de atender apenas ao público interno (funcionários em fase de aposentadoria) da Universidade onde é desenvolvido. Entretanto, após o interesse de diversos canais de comunicação na divulgação do mesmo, obteve-se ampla repercussão, inclusive por parte de empresas, resultando no descobrimento de uma grande demanda por este tipo de trabalho. Desta forma, consolidou-se em um programa permanente na referida Universidade. 
O Aposenta-Ação caracteriza-se por ser um trabalho grupal em Psicologia, aberto à comunidade, cuja iniciativa partiu de um Laboratório de Informação e Orientação Profissional, de uma Universidade pública e gratuita. A idéia do Programa resultou da percepção de uma necessidade social de se falar mais a respeito da aposentadoria, por três motivos principais:

a) falta de planejamento pessoal para aposentadoria: muitos vêem este momento somente com oportunidade de descanso;

b) aumento da expectativa de vida, trazida principalmente pelos avanços da medicina e a diminuição do trabalho com exigência de alto esforço físico: se as pessoas têm vivido mais tempo, é preciso um olhar para o que elas vão fazer;

c) trabalhar na transformação da representação dos indivíduos, da sociedade e das instituições (públicas e privadas) sobre a importância do aposentado.

Segundo Soares (2002), o trabalho de orientação em grupos possibilita identificações recíprocas, enriquecimento pessoal a partir da troca de idéias, compartilhamento de experiências, possibilidade de feedback entre os próprios membros do grupo. A diversidade de situações pessoais proporciona dinamização ao grupo.

O objetivo geral definido para o Programa é desenvolver atividades grupais com pessoas que estão próximas da data de aposentadoria ou que tenham se aposentado recentemente, com intuito de prevenir os diversos problemas que a aposentadoria não-planejada pode trazer, por meio de reflexões e planejamento para esta nova etapa de vida. Para atingir este objetivo, foram delineados alguns objetivos específicos:

a) realizar atividades grupais, visando à integração e à troca de experiências;

b) instigar o grupo a refletir e discutir sobre esta nova fase, possibilitando a busca de entendimento sobre as questões resultantes da mudança de vida na aposentadoria;

c) contribuir para o processo cultural do grupo, trazendo informações de diversas áreas como: saúde, investimentos, previdência, esportes, família, direitos, etc;

d) orientar as pessoas para buscarem um novo projeto de vida que lhes satisfaça e assumirem novas atividades baseadas no conhecimento dos interesses pessoais e de novas motivações. 
O Programa Aposenta-Ação oferece um serviço novo e gratuito à comunidade, tendo como público-alvo pessoas em fase de aposentadoria ou recém-aposentadas. Cada grupo de 15 a 20 integrantes é coordenado por dois estudantes de Psicologia e supervisionado por um Professor do Departamento de Psicologia, especialista em orientação profissional e de carreira. Além disso, há a participação de diversos profissionais de outras áreas do conhecimento (como detalhado a seguir), de forma a tornar o trabalho interdisciplinar.

Ao se nomear o Programa com o título Aposenta-Ação, idealizouse associar o termo aposentadoria com ação, significando que esta fase da vida pode e deve mobilizar a pessoa para atividades não desenvolvidas no seu período de trabalho produtivo. Este é seu momento de concretizar sonhos e desejos, muitas vezes deixados de lado em função das exigências do trabalho regrado e da conseqüente falta de tempo para tais realizações.

O pressuposto é de que, ao participar do Programa Aposenta-Ação, o sujeito não seja somente orientado para um trabalho de autoconhecimento, revisão de prioridades e elaboração de novo projeto de vida para esta nova fase, mas também, por meio de trocas e experiências entre os participantes dos grupos, possa descobrir novas oportunidades de inserção social.

\section{Planejamento das Atividades e Realização dos Encontros}

O Programa Aposenta-Ação baseia-se nos estudos realizados por Soares (2002) sobre a formação de grupos em Orientação Profissional (OP). Segundo a autora, a OP tem por objetivo trabalhar a relação homem X trabalho, seja ela na escolha de um curso superior (OP propriamente dita), no início da carreira (Planejamento de Carreira) ou na Preparação para a Aposentadoria, ou o término desta relação homem X trabalho. Baseou-se, então, o trabalho no tripé: conhecimento de si mesmo, conhecimento do mundo (o que é possível fazer sem o trabalho) e projeto de futuro.

$\mathrm{Na}$ elaboração do Programa foram definidas as temáticas a serem abordadas nos encontros, a partir da experiência com os outros tipos de grupos mencionados anteriormente. Como o foco dos aposentados é na saída do mundo do trabalho, foram escolhidos temas relacionados a esta situação. O ócio tornou-se um tema bastante importante nas discussões grupais. Entre as temáticas, citam-se: 

a) mudanças na vida e escolhas passadas, presentes e futuras;
b) trajetória profissional;
c) o mundo do trabalho e a previdência;
d) a família e o aposentado;
e) relacionamento social;
f) organização de pequenos negócios e finanças pessoais;
g) saúde, esporte e lazer na aposentadoria;
h) a busca de si mesmo;
i) o ócio: é possível vivê-lo;
j) projeto futuro.

\subsection{Primeira Etapa: entrevistas iniciais}

Anteriormente à divulgação em meios de comunicação, foram contatados, por meio de telefonemas, vinte e um possíveis interessados, pré-aposentados indicados pelo Departamento de Pessoal da Universidade onde o Programa seria desenvolvido. Desse total, quatro não tiveram interesse no trabalho e treze, ou não tiveram disponibilidade de tempo, ou não compareceram às entrevistas agendadas. Concretizaram-se, assim, entrevistas iniciais com apenas quatro interessados.

Passar por esta dificuldade para colocar o Programa em prática foi importante, pois possibilitou aos coordenadores uma primeira conclusão: o interesse na preparação para aposentadoria deve ser opção da própria pessoa. Assim, o impulso de procurar ajuda e conhecimento de si mesmo é o melhor convite à preparação e participação no grupo.

A divulgação do Programa à comunidade proporcionou mais de cinqüenta pré-inscrições. Realizaram-se as entrevistas iniciais com mais doze interessados e ficou composto o primeiro grupo com dezesseis integrantes. Os demais interessados foram informados que permaneceriam em espera para próximos grupos.

As entrevistas iniciais foram realizadas individualmente, com duração de cerca de uma hora e com a participação do interessado e das coordenadoras. Para a realização das mesmas, foi elaborado e seguido o roteiro:

a) dados pessoais como: nome, data de nascimento, escolaridade, estado civil. Preenchimento da ficha cadastral do Serviço de Atendimento Psicológico (SAPSI); 
b) sempre atuou na mesma área ou teve outras experiências profissionais?

c) que tipos de atividades desempenha ou desempenhava em seu trabalho?

d) quais aspectos você considera mais marcantes da sua vida profissional? O que mais gostou de fazer; o que menos gostou de fazer?

e) quais são os comentários de sua família quando falam a respeito de sua aposentadoria?

f) o que você gosta de fazer em suas horas vagas?

g) como são seus relacionamentos sociais?

h) tem idéia do que fará após se aposentar?

i) o que o atraiu a participar de um grupo de preparação para aposentadoria?

j) quais as suas expectativas, o que você espera encontrar aqui?

k) você já fez algum tipo de atendimento psicológico anteriormente? Por quais motivos?

As demandas trazidas pelos participantes nas entrevistas iniciais permitiram constatar que o Aposenta-Ação não poderia ser baseado em receitas prontas. Seria preciso trabalhar com diversidades, pois cada sujeito traz consigo sua história de vida, suas percepções e seus interesses pessoais. Entretanto, de forma generalista, alguns aspectos puderam ser percebidos na maioria dos sujeitos que realizaram as entrevistas iniciais:

a) ansiedade por não possuir novas atividades para realização após a aposentadoria;

b) dúvidas na escolha de novas atividades (para muitos o trabalho foi o único foco de atenção e meio de satisfação durante toda a vida);

c) medo do envelhecimento - muitos relacionam a aposentadoria a falta de perspectiva, a inutilidade e até com morte, apresentando extrema dificuldade de aceitação e do reconhecimento na aposentadoria. Para Amarilho (2005, p. 82): "A expectativa de afastamento, o parar de trabalhar, está diretamente relacionado ao sentimento de fim da vida." A mesma autora afirma que: "Trabalhar é viver. Trabalho é vida, a vida sem trabalho denota finitude." (2005, p. 89);

d) necessidade de trabalhar aspectos relativos a relacionamento familiar.

Os entrevistados trouxeram diversas demandas relacionadas à família, as quais se vinculam ao fato de o aposentado adquirir novos hábitos, 
diferentes daqueles que apresentava na vida laborativa, fazendo-se necessário o redesenho de papéis no núcleo familiar. Normalmente, são poucos os momentos de interação em casa, entre o pré-aposentando e os demais integrantes da família. Este fato faz com que todos os familiares se percebam com rotinas claramente definidas. Quando isso é modificado, nascem conflitos em torno da necessidade de um novo "lugar", na casa, para aquele que agora se faz mais presente. Muitas vezes, também, um novo "lugar" nos relacionamentos começa a existir, a partir das novas percepções decorrentes desta reconfiguração familiar.

Além desses aspectos, percebeu-se durante as entrevistas o quanto a identidade está relacionada com a trajetória profissional. Foram comuns falas circunstanciadas por sintomas de medo, inquietude, baixa auto-estima e, em alguns casos, até de depressão, devido ao afastamento do trabalho: "Estou muito ansiosa com a possibilidade de me aposentar, pois não tenho nada definido para minha vida ainda." (PARTICIPANTE A); "Sinto muita falta do dia-a-dia no trabalho, das responsabilidades, estou me vendo 'sem nada." (PARTICIPANTE B); "Devo pensar em minha vida profissional no passado ou no futuro?" (PARTICIPANTE C).

A realização da entrevista inicial é fundamental para verificar as expectativas individuais e nortear o planejamento dos encontros a partir de interesses identificados. Após a realização das referidas entrevistas, seguiram-se reuniões de planejamento entre os organizadores dos encontros e realizou-se o contato com profissionais de outras áreas, conforme assuntos de interesse do grupo.

\subsection{Segunda Etapa: planejamento dos encontros}

As técnicas escolhidas foram vivências, dinâmicas de grupo, discussões informativas e palestras sobre as temáticas presentes no Projeto do Aposenta-Ação. Também foram contempladas as propostas trazidas pelos participantes nas entrevistas iniciais.

3.3 Terceira Etapa: descrição dos encontros

Os trabalhos com o primeiro grupo estão descritos a seguir. Foram realizados nove encontros grupais, com a duração média de duas horas, ocorrendo com freqüência semanal. Os encontros foram organizados pro- 
curando sempre integrar a questão informativa e vivencial, pois ambas facilitam a reflexão sobre novas possibilidades da aposentadoria.

\subsubsection{Primeiro Encontro}

Realizou-se a apresentação dos integrantes no grupo, o levantamento de expectativas grupais, integração e formulação do contrato de trabalho. Neste encontro, trabalhou-se com uma técnica de apresentação através da utilização de crachás. Realizou-se o estabelecimento do contrato, com aplicação da técnica do "Novelo de Lã" (SOARES, 2002, p. 169) e uma técnica de relaxamento, a fim de possibilitar a reflexão sobre a aposentadoria como a chegada do novo.

\subsubsection{Segundo Encontro}

A temática deste encontro foi "esportes e lazer". Inicialmente, realizou-se uma palestra informativa sobre esportes, com a presença de um especialista convidado, com a apresentação de técnicas sobre a correta realização de atividades físicas, bem como propostas para o início da prática esportiva, inclusive com as alternativas existentes dentro da própria universidade, como o Núcleo de Estudos da Terceira Idade (NETI). Também, foi realizada uma dinâmica de grupo para discussão sobre atividades de lazer, com foco nas possibilidades para a região. Em ambas as situações - esporte e lazer —, discutiu-se a importância da inserção social promovida pelas práticas de atividades físicas.

\subsubsection{Terceiro Encontro}

Realizou-se uma palestra sobre o tema: a família e o aposentado, mudanças e escolhas da aposentadoria. Teve como objetivo promover uma reflexão sobre a implicação dos novos papéis que são construídos com a aposentadoria e a compreensão das novas formas de relações sociais estabelecidas neste momento. $\mathrm{O}$ tema relações familiares é polêmico e gerou grande ansiedade entre os participantes, bem como levou a reflexões sobre como eram as relações entre gerações passadas e como são agora, principalmente na questão pais e filhos. No mesmo encontro, solicitou-se aos integrantes que realizassem a "Técnica Gosto e Faço" (LUCCHIARI, 1992, 
p. 44-45), a qual consiste em responder a quatro perguntas, organizadas em quadrantes: o que eu gosto e faço; o que gosto e não faço; o que não gosto e faço; e o que não gosto e não faço. Tal técnica favorece a análise de como a pessoa se posiciona em relação às suas necessidades, desejos e impedimentos, e possibilita a visualização dos aspectos que precisam de maior atenção, como as coisas que gosta e não faz (porque não faz?). Este questionamento favorece a visualização de novas oportunidades a serem buscadas no planejamento pessoal do futuro.

\subsubsection{Quarto Encontro}

Neste encontro, procurou-se atender a uma demanda trazida pelos participantes quanto a esclarecimentos de aspectos jurídicos, os trâmites do processo de aposentadoria, cálculos e regras de benefícios pós-aposentadoria. Para prestar estas informações e responder a dúvidas, foi convidado um especialista na área, responsável por esta área de informação ao usuário do INSS. Num segundo momento, a fim de dar continuidade ao processo vivencial realizou-se a técnica âncoras de carreira (SHEIN, 1995). Solicitou-se que todos respondessem as questões pensando em termos da aposentadoria e não do início da carreira, como normalmente é utilizada em grupos de OP. Cada integrante teve a oportunidade de comentar o que lhe chamou atenção nos resultados alcançados.

\subsubsection{Quinto Encontro}

O objetivo deste encontro foi discutir o tema empreendedorismo e a organização de pequenos negócios após a aposentadoria, por solicitação de alguns integrantes do grupo, e contou com a participação de especialista na área, técnico do Serviço de Apoio Brasileiro às Micro e Pequenas Empresas (SEBRAE).

\subsubsection{Sexto Encontro}

Foi promovida uma palestra sobre saúde, prevenção de doenças, sexualidade e qualidade de vida, com temas que tangenciam as mudanças relativas ao processo de envelhecimento, a qual foi ministrada por uma médica, especialista em geriatria. Para este encontro deixou-se livre a par- 
ticipação de familiares, tendo sido bem aceito pelo grupo, trazendo esposas e maridos para participarem da reunião.

\subsubsection{Sétimo Encontro}

Realizou-se a técnica da "Viagem ao Passado, Presente e Futuro" (LUCCHIARI, 1992, p. 47), com a finalidade de despertar a discussão das experiências individuais e da relação destas com a nova etapa da aposentadoria. Também foi solicitado aos integrantes que construíssem um cartaz com a linha da vida, explicitando de forma artística aspectos marcantes (sociais, familiares, históricos e profissionais) e o trouxessem para o próximo encontro. A técnica é uma adaptação do gráfico da vida profissional (SOARES, 2002, p. 173).

\subsubsection{Oitavo Encontro}

Realizou-se reflexão em duplas sobre a história de vida, através da apresentação da técnica "linha da vida". Logo após, a história de cada um foi contada ao grupo pelo outro colega da dupla. Foi um encontro importante onde os participantes puderam avaliar toda a sua história de vida, as escolhas feitas nos diferentes momentos da vida e como estas foram construindo uma trajetória de vida. Este encontro mobilizou o grupo, pois puderam perceber como sua história de vida é construída pelas escolhas realizadas ao longo desta e as possibilidades de novas escolhas neste momento da aposentadoria.

\subsubsection{Nono Encontro}

Foi solicitada a elaboração de um roteiro de planejamento de vida para um ano, sugerindo as temáticas: ocupação, desenvolvimento pessoal, saúde, bem-estar e relacionamentos. O planejamento foi discutido na entrevista final integrativa. Neste encontro realizamos a "Técnica de Auto-Avaliação" proposta por Soares (2002, p. 186), a partir da seguinte consigna:

As frases a seguir o ajudarão a refletir sobre o trabalho realizado. Procure pensar tanto em termos da aposentadoria e do seu momento de vida: 
a) antes de iniciar os encontros eu me sentia...;

b) o que eu sentia quando participava dos encontros e realizava as atividades solicitadas?

c) quais as atividades que mais gostei? Por quê?

d) quais as atividades que menos gostei? Por quê?

e) os encontros me auxiliaram em...;

f) agora estou me sentindo...;

g) você recomendaria a um amigo /conhecido? Por quê?

h) sugestões.

3.4 Quarta Etapa: entrevistas integrativas

Da mesma forma que na entrevista inicial, a entrevista integrativa foi realizada individualmente, com duração de cerca de uma hora. A proposta foi discutir o planejamento pós-aposentadoria elaborado pelos integrantes e promover uma avaliação individual da compreensão da aposentadoria e da sua participação no grupo. Os participantes avaliaram o Programa como muito importante e válido para o seu processo pessoal de aposentadoria. A maioria referiu sentir-se mais tranqüilo e preparado para enfrentar esta nova fase da vida, com mais ação e determinação de seus objetivos para o futuro: "Eu sentia uma angustia muito grande, só de pensar em me aposentar. Agora, depois de participar do grupo, não sinto mais esta angústia. Estou tranqüila!" (PARTICIPANTE A).

\section{Resultados do Trabalho}

O momento da vida relacionado à aposentadoria é repleto de transformações. Citamos algumas delas: primeiro, nesta etapa da vida acontecem as mudanças biológicas, relacionadas ao envelhecimento; segundo, a conjuntura familiar se desestabiliza com a saída dos filhos de casa, a chegada dos netos e o reencontro do casal dentro da mesma casa, muitas vezes, sem atividades para fazer; terceiro, a construção de um novo papel social, decorrência da "perda" da identidade profissional, do status social trazido pelo nome de um cargo ou profissão, o que requer a construção pessoal do papel de ser aposentado.

Esta passagem da vida profissional ativa para a aposentadoria "inativa" normalmente acontece sem qualquer planejamento ou reflexão. 
Muitos vêem a aposentadoria como um momento de parar, de descansar, simplesmente, e comentam:

A aposentadoria está relacionada com acomodação, muito semelhante a quando estou de férias, ou uma folga prolongada [. . .] Durmo até tarde, não uso um salto-alto, não preciso me preocupar tanto com minha aparência [... . É hora de relaxar! (PARTICIPANTE D).

Quando a aposentadoria se dá desta forma, não demoram a surgir os problemas, como isolamento, tristeza e depressão, bem como diversas doenças - resultado não somente do processo de envelhecimento, mas também da ruptura com o mundo do trabalho.

É possível e necessário desenvolver algumas coisas, nesta etapa da vida [. . . A A disciplina é, talvez, a mais importante [. . . Independente se você tem ou não um compromisso com o trabalho, é preciso manter a disciplina sobre si mesmo, não relaxando os cuidados consigo. (PARTICIPANTE I).

Observou-se, em cada encontro, que o compartilhamento de vivências e a contribuição dos integrantes entre si na preparação para a aposentadoria aumentavam. O trabalho grupal é uma excelente ferramenta para este tipo de atividade, por proporcionar aproximação entre as pessoas, a troca de experiências, criação de novos vínculos e a superação de muitos mitos acerca do aposentar-se. Alguns comentários, como o que segue, atestam isto:

Esta atividade mexeu bastante comigo [...] contribuiu, inclusive, para que eu já promovesse algumas mudanças em casa, com base nas reflexões que o grupo está possibilitando. Meus filhos, inclusive, estão percebendo as alterações e estranhando, me questionando sobre o que este grupo estaria fazendo comigo, pois tenho manifestado mais minhas opiniões dentro de casa [ . . ] sinal de que estão percebendo melhor que também tenho interesses e vontades. (PARTICIPANTE F).

Estud. interdiscip. envelhec., Porto Alegre, v. 12, p. 143-161, 2007. 
O procedimento de trabalho em grupo foi atrativo aos participantes, devido à participação ativa nas atividades propostas, comprometimento e a presença destes nos encontros ao longo do Programa.

Considera-se importante, também, perceber uma evolução no pensar a aposentadoria. Inicialmente, apresentaram-se muitas dúvidas, resistência de alguns e pensamentos ambíguos de outros, além de um vínculo forte com o mundo do trabalho, principalmente por parte daqueles que ainda estavam trabalhando: "O que mais me preocupa, quando penso na aposentadoria, é o temor de ficar sem ter o que fazer e com isto desenvolver alguma doença." (PARTICIPANTE N); "O trabalho é um bom pretexto para se produzir e uma obrigação que acaba por desencadear as demais coisas da vida, os demais compromissos, a motivação para se arrumar, se produzir e cuidar da aparência.” (PARTICIPANTE G).

A cada encontro, novas discussões eram desencadeadas e aconteciam novas elaborações sobre o que se constitui a aposentadoria, sendo extremamente positivo para o alcance dos objetivos deste trabalho. Alguns comentários ilustram:

\footnotetext{
Não consigo relacionar aposentadoria com solidão. Não tenho o temor da solidão. Este não é um problema, considero que as pessoas devem procurar visitar familiares, andar com os amigos, etc. São inúmeras as sugestões de atividades para este novo período! (PARTICIPANTE J).
}

"Quero é me aposentar, ainda novo, com maiores condições para me adaptar às mudanças.” (PARTICIPANTE M).

Cabe aqui destacar, também, a escolha apropriada de atividades desenvolvidas neste Programa: as técnicas psicológicas para reflexão sobre o passado, o presente e o futuro, as palestras informativas e as discussões grupais. Todas se constituíram em estratégias de intervenção e contribuíram para o processo de planejamento da aposentadoria. Ainda, é preciso considerar como fundamental a interdisciplinaridade adotada, principalmente nas palestras, pois um profissional isolado (no caso específico profissional da Psicologia) dificilmente conseguiria atender a todas as demandas trazidas pelos participantes.

Em meio a inúmeras indagações do aposentar-se, uma certeza se impõe: a aposentadoria transforma completamente a vida da pessoa, altera 
rotinas e hábitos, expectativas e relacionamentos. Em decorrência disso, entende-se como fundamental uma boa preparação do sujeito para a compreensão e enfrentamento dessas mudanças, bem como a reflexão sobre o planejamento pessoal para o futuro.

Em relação à formação profissional e à atuação enquanto psicólogos, foi possível perceber a necessidade de aprimoramento, tendo em vista a escassez de literatura e estudos nesta área. Para os coordenadores, a nível pessoal, o trabalho constitui-se em um grande desafio e aprendizado, devido à necessidade de construção e estruturação do Programa, processo no qual esta idéia foi transformada em realidade.

Hoje, muito mais do que uma iniciativa que deu certo, é preciso considerar o Programa Aposenta-Ação como resultado de trabalho conjunto e do comprometimento de cada um dos envolvidos.

\title{
APOSENTA-AÇÃO: program preparation for retirement
}

\begin{abstract}
This paper presents a discussion concerning the subject "retirement", and describes the stages of development of a Program of Preparation for Retirement APOSENTA-AÇÃO. It was proven, through the consulted bibliography and the related Program that, for the great majority of the people, the retirement is not followed by reflections on the future project and, as a result, it gives the opportunity to the sprouting of diverse problems of psychological and social order.Thus, one concludes that the orientation and psychological accompaniment in the retirement phase consist in basic facilitation to face this new stage of life.

Keywords: Retirement. Program of Preparation. Orientation.
\end{abstract}

\section{REFERÊNCIAS}

AMARILHO, Cristina Bacigaluz. As Implicações da Perspectiva de Afastamento do Trabalho e Projeto de Vida no Discurso do Executivo-Empreendedor-Idoso. 2005. 100 f. Dissertação (Mestrado em Psicologia)-Instituto de Psicologia, Universidade Federal do Rio Grande do Sul, Porto Alegre, 2005. 
BERNHOEFT, Renato. Trabalhar e Desfrutar: equilíbrio entre vida pessoal e profissional. São Paulo: Nobel, 1994.

BOTH, Tatiana Lima. Jubilamento: o interdito de uma vida de trabalho e suas repercussões na velhice. 2004. 96 f. Dissertação (Mestrado em Psicologia)-Instituto de Psicologia, Universidade Federal do Rio Grande do Sul, Porto Alegre, 2004.

CARLOS, Sergio Antonio et al. Identidade, Aposentadoria e Terceira Idade. Estudos Interdisciplinares sobre o Envelhecimento, Porto Alegre, v. 1, p. 77-88, 1999.

DEJOURS, Christophe et al. Psicodinâmica do Trabalho: contribuições da escola dejouriana à análise da relação prazer, sofrimento e trabalho. São Paulo: Atlas, 1994.

FERREIRA, Aurélio Buarque de Holanda. Novo Dicionário Aurélio da Língua Portuguesa. 2. ed. Rio de Janeiro: Nova Fronteira, 1986.

FRANÇA, Lucia. Preparação para a Aposentadoria: desafios a enfrentar. In: VERAS, Renato Peixoto. Terceira Idade: alternativas para uma sociedade em transição. Rio de Janeiro: Relume-Dumará, 1999. P.11-34.

LUCCHIARI, Dulce Helena Penna Soares. Pensando e Vivendo a Orientação Profissional. São Paulo: Summus, 1992.

MARX, Karl. O Capital: crítica da economia política. São Paulo: Abril Cultural, 1984.

RODRIGUES, Milena et al. A Preparação para a Aposentadoria: o papel do psicólogo frente à essa questão. Revista Brasileira Orientação Profissional, Ribeirão Preto, v. 6, n. 1, p. 53-62, jun. 2005.

SANTOS, Maria de Fátima de Souza. Identidade e Aposentadoria. São Paulo: EPU, 1990.

SHEIN, Edgar. A Identidade Profissional. São Paulo: Nobel, 1995. 
SOARES, Dulce Helena Penna. A Escolha Profissional: do jovem ao adulto. São Paulo: Summus, 2002.

WITCZAK, Marcus Vinicius Castro. Envelhecer ao Aposentar-se: discutindo a aposentadoria masculina, o envelhecer e o subjetivar. 2001. 120 f. Dissertação (Mestrado em Psicologia)-Instituto de Psicologia, Universidade Federal do Rio Grande do Sul, Porto Alegre, 2001.

WITCZAK, Marcus Vinicius Castro. Envelhecer ao Aposentar-se: discutindo a aposentadoria masculina, o envelhecer e o subjetivar. Santa Cruz do Sul: EDUNISC, 2005.

ZANELLI, José Carlos; SILVA, Narbal. Programa de Preparação para a Aposentadoria. Florianópolis: Insular, 1996.

Recebido em: 26/06/2007

$1^{a}$ revisão: $14 / 10 / 2007$

Aceite final: 05/11/2007 